http://jmscr.igmpublication.org/home/ ISSN (e)-2347-176x ISSN (p) 2455-0450

crossref DOI: https://dx.doi.org/10.18535/jmscr/v8i4.26

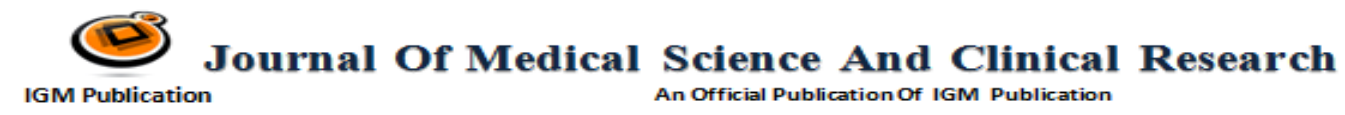

\title{
Bladder Cancer: is Radiotherapy being Underutilized?
}

Authors

\section{Dr P.Sridhar ${ }^{1}$, Dr Vijay C.R. ${ }^{2}$, Dr Rasla Parween ${ }^{3}$, Dr Mahantesh A.S ${ }^{4 *}$,}

Dr Murali Krishna ${ }^{5}$, Dr Lokesh Vishwanath ${ }^{6}$, Dr Naveen Thimmiah ${ }^{7}$

${ }^{1}$ Assistant Professor, Department of Radiation Oncology, Kidwai Memorial Institute of Oncology, Bangalore-29

${ }^{2}$ Associate professor, Department of Epidemiology and Biostatistics, Kidwai Memorial Institute of Oncology, Bangalore-29

${ }^{3}$ Post Graduate Student, Department of Radiation Oncology, Kidwai Memorial Institute of Oncology Bangalore-29

${ }^{4}$ Assistant Surgeon, Kidwai Memorial Institute of Oncology, Bangalore-29

${ }^{5}$ Post Graduate Student, Department of Radiation Oncology, Kidwai Memorial Institute of Oncology, Bangalore-29

${ }^{6}$ Professor and Head of Department, Department of Radiation Oncology, Kidwai Memorial Institute of Oncology, Bangalore-29

${ }^{7}$ Professor and Head of Unit, Department of Radiation Oncology, Kidwai Memorial Institute of Oncology, Bangalore-29, India *Corresponding Author

Dr Mahantesh A.S

\section{Abstract}

Background of the Study: Bladder cancer is the 2nd most common Genitourinary cancer. There are 424082 male Bladder cancer cases and 125311 female bladder cancer cases worldwide. In India, there were 14729 male and 4197 female patients who had Bladder cancer. According to HBCR (2016) there were 71 male and 21 female bladder cancer patients. Radical cystectomy has been considered as the gold standard treatment of choice and only curative therapy for Bladder cancer, thereby underutilizing the trimodality therapy consisting of Transurethral Resection of Bladder Tumor (TURBT) and Chemoradiation,which helps in maintaining patient's native bladder and improving quality of life. Radical cystectomy with pelvic node dissection is associated with potential morbidity and can be avoided in selected group of patients. This study is to assess the Urinary bladder cases who underwent treatment and the outcomes of Bladder Preservation Therapy (BPT) and quality of life.

Materials and Methods: Bladder cancer patients who reported to Department of Radiation Oncology in Kidwai Memorial Institute of Oncology were analyzed from January 2019 to February 2019. A total of 17 patients were referred for Radiotherapy treatment which included Haemostatic Radiotherapy, Adjuvant Radiotherapy, Radical Radiotherapy, Palliative Radiotherapy. All the Patients underwent basic investigations and work up was done. Based on the Clinical stage of disease and general condition of Patients, Radiotherapy was planned. Conformal Radiotherapy technique was delivered and Clinical outcomes were analysed.

Results: 4 patients received hemostatic radiotherapy and had good bleeding control within 24 to hours, 4 patients received Radical radiotherapy of which 2 patients had stable disease and 2 patients had complete response. 2 patients underwent Trimodality treatment and 1 patient received adjuvant radiotherapy, all of them had no evidence of disease on cystoscopy. 3 patients received Palliative radiotherapy and had good pain relief from bone metastasis. About $76 \%$ of patients had gastrointestinal toxicity (grade.1-46\% and grade.2-30\%) and 70\% of patients had genitourinary toxicity (grade. 1 - 30\% and grade.2-40\%).

Conclusions: Trimodality therapy provides equal oncologic outcomes and reduces the morbidity associated with radical cystectomy. Selection of cases is the most crucial step for better tumour control and improving quality of life and hence Trimodality therapy must be judiciously advocated to the ideal bladder cancer cases. Organ preservation therapy for bladder cancer is an effective alternate approach in specific subset of patients. The need for multidisciplinary clinics must be emphasized and each case must be dealt critically for bladder preservation therapy. Radical cystectomy must be reserved for recurrent cases and non-responders of chemoradiotherapy. The optimal usage of radiation technique, fractionation schedule, chemotherapeutic agent individualized for the patients and also targeted therapy will definitely bring about better results in management of bladder cancer.

Keywords: Bladder Preservation Therapy, Muscle-Invasive Bladder Cancer, Radical Cystectomy, Image Guided Radiotherapy, Transurethral Resection of Bladder Tumour. 


\section{Introduction}

Bladder cancer is the second most common genitourinary cancer after Prostate cancer. There are 424082 male Bladder cancer cases and 125311 female bladder cancer cases worldwide ${ }^{(1)}$. It is more commonly seen among men than women in the world. It is mostly seen in population commonly exposed to chemicals. Incidence of Bladder cancer was high in workers of Dye factories (Naphthylamine exposure), Rubber and Paint industries (Aralymine exposure), Textile industries. Tobacco smoking is also a main risk factor for Bladder cancer. In India, there were 14729 male and 4197 female patients who had Bladder cancer. In the urban population-based cancer registries, the incidence is more compared to rural areas according to recently published Indian Council of Medical Research (ICMR) data. In our Hospital-Based Cancer Registry (2016), there were 71 male and 21 female bladder cancer patients $^{(2)}$.

Trimodality bladder preservation therapy is an alternative treatment option to radical cystectomy in selective group of patients with Muscle Invasive Bladder Cancer (MIBC). Radical cystectomy is always considered as the gold standard treatment of choice and curative therapy in Urological practice. Trimodality therapy (Transurethral Resection of Bladder TumourTURBT, followed by Chemoradiotherapy) is being under utilized as most of the patients who have undergone radical cystectomy could have been subjected to trimodality therapy. It helps in maintaining the patient's native bladder and maximizing the Quality of Life (QOL) as the maximum bulk of cases are seen in elderly patients.

\section{Need For the Study}

Bladder cancer consists of heterogeneous group of patients and identifying the subset of patients for Trimodality Therapy (TMT) is a challenge. This study is to assess the outcomes of carcinoma urinary bladder cases referred to Regional Cancer Centre including bladder preservation therapy and quality of life. There are no randomized studies comparing radical cystectomy and bladder preservation therapy till date.

Radical cystectomy and pelvic lymph node dissection has potential morbidity. Radical Cystectomy involves the removal of bladder, prostate, pelvic lymph node dissection in males and removal of bladder, urethra, anterior vaginal wall, uterus, pelvic lymph node dissection in females. Extended lymphadectomy may also be needed at times. Urinary diversion is performed with a bowel loop, most common non-continent type is ileal conduit and continent type is orthotopic neobladder or an abdominal pouch. Avoiding the complications of surgery like electrolyte abnormalities, renal calculi, bacteruria, sepsis, malabsorption, short bowel syndrome, urinary incontinence, ureteral obstruction, Bowel obstruction in patients with co-morbidities must be done seriously. Trimodality therapy gives the benefit of the patient retaining the bladder, minimizing the post-operative complications and maximizing quality of life for the rest of the life.

The primary goal of bladder preservation therapy is cancer control and preserving the native bladder is the secondary goal. Benefits of bladder preservation therapy are tumour eradication by using the synergistic action of chemoradiotherapy (3). Micro-metastasis outside the field of radiation is tackled by chemotherapy. Patient selection is very critical for bladder preservation therapy. Institutional tumour board meetings should be conducted periodically and identifying the trimodality therapy cohort is very crucial as it has equal Oncologic outcomes with better quality of life in older patients. Very few cases are referred for Radiotherapy though bladder cancer can be treated in all clinical scenarios.

In a Canadian study by Walker et al, on Clinical practitioners it was observed that 64 Urologists referred only 2 out of 10 cases for radiotherapy and 26 Medical oncologists referred 2 out of 8 cases for radiation who were not referred by Urologists. Overall 28 Radiation oncologist treated 5 out of 10 cases for radiotherapy 
(Hemostatic/ Radical/ Adjuvant/ Palliative) who were referred to them due to various reasons ${ }^{(4)}$.

In U.K SPARE trial (Randomised trial of Selective Bladder Preservation against Radical cystectomy) for muscle invasive $\mathrm{T} 2 / \mathrm{T} 3$ cases which is an ongoing feasibility study, results are awaited. Radiotherapy is used very sparingly in U.S (10\%) and about (25\%) in Scandinavian countries and upto $(50 \%)$ in $\mathrm{U} . \mathrm{K}^{(5)}$. With the advent of newer Conformal radiotherapy delivery techniques like Intensity Modulated Radiotherapy, Image Guided Radiotherapy, Volumetric Modulated Arc Therapy can be delivered to achieve optimal therapeutic ratio. We analyzed the bladder cancer patients who received radiotherapy and evaluated the clinical outcomes and impact on Quality of Life.

\section{Materials and Methods}

Bladder cancer patients who reported to the Department Of Radiation Oncology in Kidwai Memorial Institute of Oncology were analyzed from January 2019 to February 2020. Complete History, General Physical examination, Blood work up, Urine cytology, Chest X-Ray, Cystoscopy and pyelography, C.T scan/MRI scan, Bone scan was done. A total of 17 patients were referred for radiotherapy treatment. 4 patients were referred for hemostatic radiotherapy, 4 patients for radical radiotherapy, 1 patient for adjuvant radiotherapy, 2 patients for trimodality therapy, 3 patients were referred for palliative radiotherapy and 3 patients did not give consent for radiotherapy, so were referred to Pain relief and best supportive care.

Hemostatic Radiotherapy: About $75 \%$ of Bladder cancer patients present with hematuria. Hemostatic radiotherapy was considered for 4 patients and was found to be better in the control of hemostasis as the patients already had comorbid conditions like uncontrolled hypertension, diabetes mellitus, ischemic heart disease and were not suitable candidates for any surgical intervention. RT dose of $8 \mathrm{~Gy}$ in single fraction for 2 patients and $20 \mathrm{~Gy}$ in 5 fractions for 2 patients was considered (Fig.1). Hemostasis was achieved in 24 to 72 hours following Radiotherapy delivery and improvement in general condition was observed.

Radical Radiotherapy: Radical radiotherapy was considered in 4 patients who were elderly with high risk features for whom surgery was deferred in 2 cases and 2 patients did not give consent for Surgery. Radical Radiotherapy dose of 64 to 68 Gy was delivered (Fig.2). Image Guided Radiotherapy technique was selected and setup was done daily for 3 days followed by weekly once.

\section{Trimodality Therapy (Trans Urethral resection} of Bladder Tumour + Chemoradiotherapy):

Maximal transurethral resection of bladder tumour must be done aggressively in ideal patients who will be subjected to bladder preservation therapy. The ideal candidates for bladder preservation therapy are: solitary early stage lesion, T2 T3 N0 Mo cases, No carcinoma in-situ seen, unifocal lesions, no hydronephrosis, complete TURBT is possible, transitional cell carcinoma / urothelial carcinoma, Non constricted bladder.

The high-risk features consists of: $\mathrm{T} 4$ disease, node positivity, metastatic disease, carcinoma insitu present, multifocality, hydronephrosis, incomplete TURBT, variant histopathological features including pure squamous variant, adenocarcinoma, small cell carcinoma, sarcomatoid variant. These patients with high risk features must be considered for neoadjuvant chemotherapy followed by radical cystectomy or taken up for radical cystectomy with diversion procedures directly if the patients are surgically suitable for the same. Patients who have complete response must be followed up closely by cystoscopy and imaging (CT/MRI) with radical cystectomy reserved for recurrences. Patients must be counselled thoroughly regarding orthotopic neobladder after pelvic irradiation and also the functional outcome of the procedure ${ }^{(6,7)}$.

Adjuvant Radiotherapy: Adjuvant radiotherapy can reduce the local failure rate and thereby improve the overall survival. It was considered in 
one patient with high risk recurrence indications like positive margins, incomplete TURBT, high grade disease, lymphovascular invasion and node positive case. Adjuvant Radiotherapy dose of 50.4 to $60 \mathrm{~Gy}$ at 1.8 to $2 \mathrm{~Gy}$ per fraction was delivered by conformal technique (Fig.3). Adjuvant radiotherapy was associated with the improvement of overall survival among patients with positive surgical margins among all other high risk post operative features $^{(8,9)}$.

Palliative Radiotherapy: Approximately 1/3rd of patients with muscle invasive bladder cancer develop metastasis by lymphatic spread paraaortic nodes are involved; bone and lungs are most common metastatic sites by hematogenous spread (Fig.4). Palliative radiotherapy was given to 3 patients. 2 patients with bone metastasis received dose of $20 \mathrm{~Gy}$ in 5 fractions and 1 patient with lung, liver metastasis received 30 Gy in 10 fractions to pelvis for pain relief.

Quality of Life: Acute and Late toxicities were analysed. Acute toxicities include frequency, urgency, dysuria, nausea and vomiting, hematological toxicity, gastrointestinal toxicity (enteritis) and genitourinary toxicity (cystitis, proctitis). Late toxicities include hemorrhagic cystitis, ureteral stricture, urethral stricture, contracted bladder and proctitis ${ }^{(10)}$.

Radiotherapy Dose: Traditionally 4-field technique was used to treat the bladder cancer. Now the patient must ideally be treated by Image Guided Radiotherapy. Patient must be in supine position with empty bladder. The patient is asked to void 15 minutes before the setup is taken every day. Initial dose of 40 to $45 \mathrm{~Gy}$ to bladder and true pelvis is planned at $1.8 \mathrm{~Gy}$ to $2 \mathrm{~Gy}$ per fraction. Cystoscopic evaluation must be done and the treatment portals must be coned down limiting to the gross residual disease with margins boosting to a total dose of 64 to $68 \mathrm{~Gy}$. For non-responders or patients with progressive disease radical cystectomy is advised.

In Obese patient's, prone position with belly board is also advisable as irradiation to the bowel will be minimized thereby reducing gastrointestinal toxicities. For better radiotherapy delivery patients are advised to empty their bladder. In patients who have increased gastrointestinal toxicities in the initial phase of treatment a particular bladder protocol must be followed everyday with $100 \mathrm{ml}$ of water intake, thereby pushing the bowel loops away from the radiation portal and limiting enteritis. Bladder exhibits variation in the size and shape dynamically. We see antero-posterior, rightleft, superior- inferior variation during inter and intra fraction treatment delivery. So, an ideal Planning Target Volume (PTV) margin of 1.5$2 \mathrm{~cm}$ must be followed based on the Institutional protocols.

Radiotherapy Technique: Radiotherapy treatment delivery has improved by leaps and bounds in the last two decades. The use of CT scan for target volume delineation and contouring the Organ at Risk (OAR) has drastically reduced the side effects of radiotherapy and thereby improving the quality of life. Intensity Modulated Radiotherapy (IMRT) improves the ability to confine the adequate dose delivery to concave tumour $^{(11)}$. Newer computer software's are developed for better optimization and treatment delivery. Bladder being a dynamic organ by itself and is surrounded by structures which take different forms and shapes throughout the day. So, real time imaging of the target volumes and critical normal structures is the key for the best and optimal real time radiotherapy treatment delivery.

Image guided radiotherapy (IGRT) is 4Dimensional radiotherapy treatment delivery technique which utilizes cone beam CT data set with planning CT data and frequent setups are done to deliver treatment optimally (12).The exact treatment position on a daily basis for each fraction is improved as the treatment field is adjusted to the delineated target volumes without margin for errors. Daily soft tissue CT guided setup has shown superior results compared to kilo voltage imaging which is based on bony landmarks thereby reducing the toxicities. This new Arsenal in Radiation Oncology 
armamentarium will definitely improve the tumour control and reduce the normal tissue toxicities and better Quality of Life.

Altered Fractionation: Different fractionation schedules have been tried in the past for bladder cancer but hyperfractionation schedules have shown better results than conventional fractionation. In a Prospective randomised trial of $\mathrm{T} 2$ to T4 patients dose of $1 \mathrm{~Gy}, 3$ times a day to a total dose of 84 Gy was delivered compared to $2 \mathrm{~Gy}$ per fraction to a total dose of 64Gy within 8 weeks with a 2 week rest period. 52\% higher mortality rate was observed in conventional fractionation arm. The 5 year and 10 year survival and local control rates in patients receiving hyperfractionation schedule was better $(\mathrm{p}=0.003)$. Late toxicities were not statistically significant between the two treatment schedules ${ }^{(13)}$. A metaanalysis of two hyperfractionated randomized trials showed decreased incidence of death ( $\mathrm{p}=0.002$ ), complete response and better survival rate $(\mathrm{p}=0.001)$ which was observed in hyperfractionated arms ${ }^{(14)}$.

RTOG 9906 evaluated twice daily irradiation with cisplatin and paclitaxel followed by 4 cycles of cisplatin and gemcitabine. Complete response rate was $87 \%$ after induction chemotherapy and 2-year survival with intact bladder was $69 \%^{(15)}$.

Table No.1: Number of cases with Age, Gender, Diagnosis, Treatment, Outcome and Toxicity

\begin{tabular}{|c|c|c|c|c|c|c|c|}
\hline \begin{tabular}{|l|} 
Case \\
number
\end{tabular} & $\begin{array}{c}\text { Age/sex } \\
\text { (M/F) }\end{array}$ & Co morbidity & Diagnosis & Surgery & Radiotherapy & Chemotherapy & Outcome \& Toxicity \\
\hline Case 1 & $71 / \mathrm{F}$ & $\begin{array}{l}\text { Diabetes, } \\
\text { Hypertension, } \\
\text { Ischemic Heart } \\
\text { Disease. }\end{array}$ & $\begin{array}{l}\text { Ca.Urinary } \\
\text { bladder }\end{array}$ & TURBT & $\begin{array}{c}45 \mathrm{~Gy} / 25 \mathrm{Fr}+ \\
9 \mathrm{~Gy} / 5 \mathrm{Fr}\end{array}$ & $\begin{array}{l}\text { Inj.Carboplatin } \\
\text { weekly }\end{array}$ & $\begin{array}{l}\text { Stable disease } \\
\text { GI- grade } 2 \\
\text { GU- grade } 2\end{array}$ \\
\hline Case 2 & $70 / \mathrm{M}$ & $\begin{array}{c}\text { Diabetes, } \\
\text { Hypertension. }\end{array}$ & $\begin{array}{l}\text { Ca.Urinary } \\
\text { bladder }\end{array}$ & TURBT & $\begin{array}{l}46 \mathrm{~Gy} / 23 \mathrm{Fr} \\
+14 \mathrm{~Gy} / 7 \mathrm{Fr}\end{array}$ & $\begin{array}{l}\text { Inj.Carboplatin } \\
\text { weekly }\end{array}$ & $\begin{array}{c}\text { N.E.D } \\
\text { GI- grade } 2 \\
\text { GU- grade } 2\end{array}$ \\
\hline Case 3 & $54 / \mathrm{F}$ & - & $\begin{array}{c}\text { Ca.Urinary } \\
\text { bladder }\end{array}$ & TURBT & $20 \mathrm{~Gy} / 5 \mathrm{Fr}$ & - & $\begin{array}{c}\text { Hemostasis achieved, } \\
\text { GU- grade1 }\end{array}$ \\
\hline Case 4 & $61 / \mathrm{M}$ & $\begin{array}{l}\text { Diabetes, } \\
\text { Hypertension. }\end{array}$ & $\begin{array}{c}\text { Ca.Urinary } \\
\text { bladder with } \\
\text { hematuria } \\
\end{array}$ & TURBT & $20 \mathrm{~Gy} / 5 \mathrm{Fr}$ & - & $\begin{array}{c}\text { Hemostasis achieved. } \\
\text { GU- grade1 }\end{array}$ \\
\hline Case 5 & $75 / \mathrm{M}$ & $\begin{array}{l}\text { Hypertension, } \\
\text { Ischemic Heart } \\
\text { Disease. } \\
\end{array}$ & $\begin{array}{l}\text { Ca.Urinary } \\
\text { bladder }\end{array}$ & TURBT & $8 \mathrm{~Gy} / 1 \mathrm{Fr}$ & - & GU- grade 1 \\
\hline Case 6 & $62 / \mathrm{M}$ & - & $\begin{array}{c}\text { Ca.Urinary } \\
\text { bladder with } \\
\text { hematuria } \\
\end{array}$ & TURBT & $20 \mathrm{~Gy} / 5 \mathrm{Fr}$ & - & Hemostasis achieved. \\
\hline Case 7 & $79 / \mathrm{F}$ & $\begin{array}{l}\text { Diabetes, } \\
\text { Hypertension. }\end{array}$ & \begin{tabular}{|c|} 
Ca.Urinary \\
bladder with liver \\
mets
\end{tabular} & TURBT & $30 \mathrm{~Gy} / 10 \mathrm{Fr}$ & - & $\begin{array}{l}\text { Pain relieved. } \\
\text { GI- grade } 1 \\
\text { GU- grade } 1 \\
\end{array}$ \\
\hline Case 8 & $71 / \mathrm{M}$ & $\begin{array}{c}\text { Diabetes, } \\
\text { Hypertension, } \\
\text { Ischemic Heart } \\
\text { Disease. } \\
\end{array}$ & $\begin{array}{l}\text { Ca.Urinary } \\
\text { bladder with } \\
\text { hematuria }\end{array}$ & TURBT & $66 \mathrm{~Gy} / 33 \mathrm{Fr}$ & - & $\begin{array}{c}\text { Hemostasis achieved, } \\
\text { Stable disease. } \\
\text { GI- grade } 2 \\
\text { GU- grade } 1\end{array}$ \\
\hline Case 9 & $65 / \mathrm{M}$ & $\begin{array}{l}\text { Hypertension, } \\
\text { Ischemic Heart } \\
\text { Disease. }\end{array}$ & $\begin{array}{l}\text { Ca.Urinary } \\
\text { bladder } \\
\text { (inoperable) }\end{array}$ & - & $64-66 \mathrm{~Gy} / 32-34 \mathrm{Fr}$ & Inj.Cisplatin weekly & $\begin{array}{c}\text { N.E.D } \\
\text { GI- grade } 1 \\
\text { GU- grade } 2\end{array}$ \\
\hline Case 10 & $79 / \mathrm{F}$ & - & \begin{tabular}{|c|} 
Ca.Urinary \\
bladder (surgery \\
denied)
\end{tabular} & - & $66 \mathrm{~Gy} / 33 \mathrm{Fr}$ & - & $\begin{array}{c}\text { Progressive Disease. } \\
\text { GI- grade } 2 \\
\text { GU- grade } 2 \\
\end{array}$ \\
\hline Case 11 & $68 / \mathrm{F}$ & - & \begin{tabular}{|c|} 
Ca.Urinary \\
bladder with bone \\
mets
\end{tabular} & - & $20 \mathrm{~Gy} / 5 \mathrm{Fr}$ & - & Pain relieved. \\
\hline Case 12 & $62 / \mathrm{F}$ & $\begin{array}{c}\text { Diabetes, } \\
\text { Hypertension. }\end{array}$ & $\begin{array}{c}\text { Ca.Urinary } \\
\text { bladder(Post Op) }\end{array}$ & - & $\begin{array}{c}45 \mathrm{~Gy} / 25 \mathrm{Fr}+ \\
9 \mathrm{~Gy} / 5 \mathrm{Fr}\end{array}$ & - & $\begin{array}{c}\text { N.E.D } \\
\text { GI- grade } 1 \\
\text { GU- grade } 2 \\
\end{array}$ \\
\hline Case 13 & $74 / \mathrm{M}$ & $\begin{array}{l}\text { Diabetes, } \\
\text { Hypertension. }\end{array}$ & \begin{tabular}{|c} 
Ca.Urinary \\
bladder with \\
hematuria, bone \\
mets, liver mets
\end{tabular} & - & $20 \mathrm{~Gy} / 5 \mathrm{Fr}$ & - & Pain relieved. \\
\hline
\end{tabular}




\section{JMSCR Vol||08||Issue||04||Page 139-147||April}

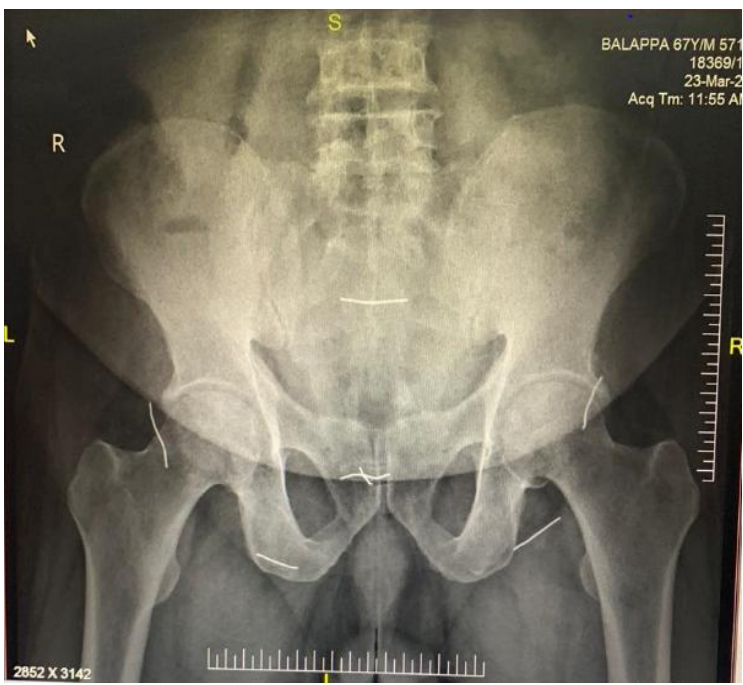

Fig.1: Hemostatic Radiotherapy

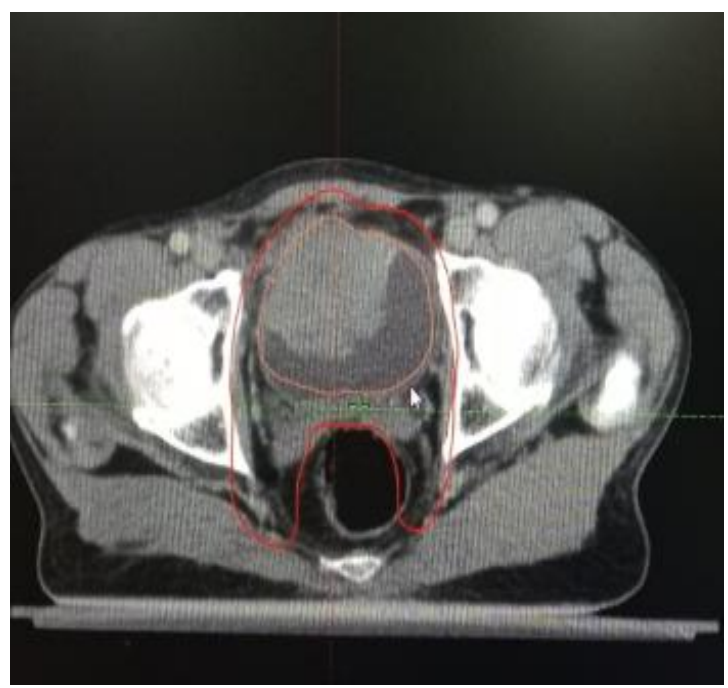

Fig.2: Radical Radiotherapy

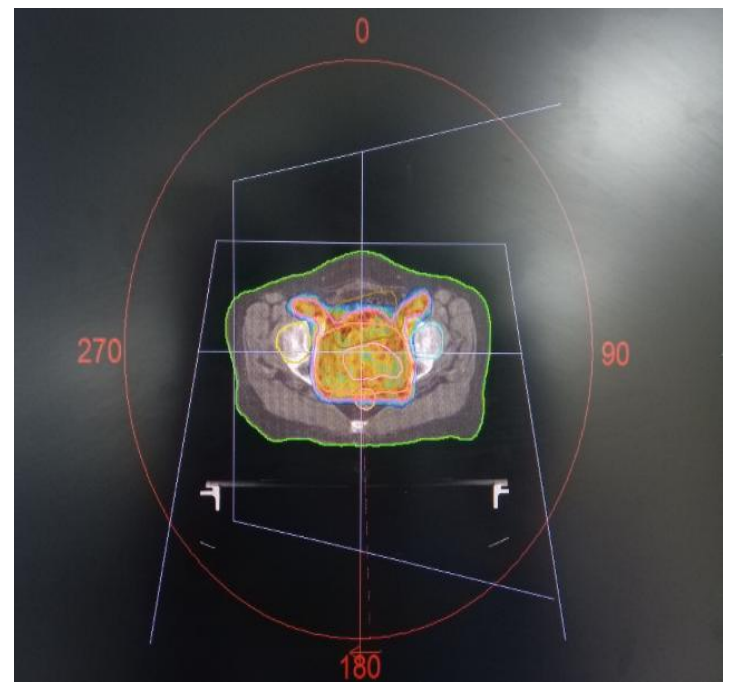

Fig.3: RT planning

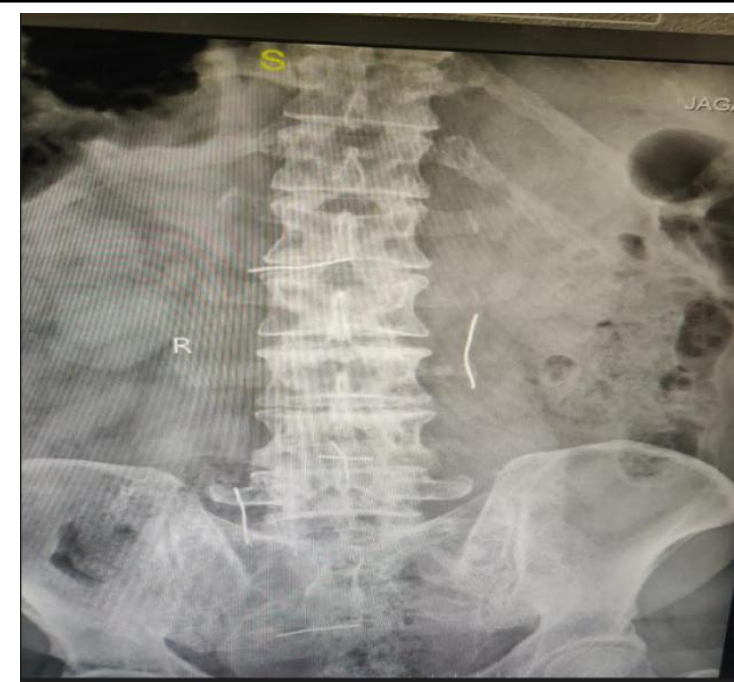

Fig.4: Palliative Radiotherapy

\section{Results}

4 patients received hemostatic radiotherapy and had good bleeding control within 24 to hours, 4 patients received Radical radiotherapy of which 2 patients had stable disease and 2 patients had complete response. 2 patients underwent Trimodality treatment and 1 patient received adjuvant radiotherapy, all of them had no evidence of disease on cystoscopy. 3 patients received Palliative radiotherapy and had good pain relief from bone metastasis. About $76 \%$ of patients had gastrointestinal toxicity (grade.1-46\% and grade. 2- 30\%) and $70 \%$ of patients had genitourinary toxicity (grade.1-30\% and grade.2- 40\%).

\section{Discussion}

Till date, there is no robust data of results from randomized controlled trials comparing radical cystectomy and bladder preservation therapy. Bladder cancer exhibits very heterogenous characteristics in patients. Historically, radical cystectomy has been considered as the gold standard of treatment. Although pathological staging can be done in radical cystectomy cases, bladder preservation therapy is no inferior which is based only on clinical staging.

Bladder preservation therapy protocol has not been made the standard of care as the patients have a varied nature of disease with different treatment lines of management in different institutions across the globe. The ultimate goal of 
either modality of treatment is optimum oncologic control and good quality of life for the patients. DW-MRI is better for predicting the response in patients who have received radiotherapy.

A retrospective study compared quality of life after radical cystectomy and bladder preservation therapy which suggested that after conservative management there is better quality of life in terms of sexual activity. Another cross-sectional study suggested that urinary symptoms (dysuria, nocturia, cystitis) and sexual function may improve after radiotherapy. Prospective trials regarding quality of life gives strong clinical evidence and practice guidelines ${ }^{(16)}$.

There are only very few studies about the impact of bladder sparing technique on quality of life especially sexual function. About half of the male patients who were treated in this study maintained satisfactory sexual function. After trimodality therapy most patients had good quality of life and sexual function compared to radical cystectomy. Urodynamic study and QOL from Harvard University concluded that about $75 \%$ of organ preserved patients had normal bladder capacity and flow rate. $85 \%$ of them had mild bladder symptoms, $50 \%$ had normal erectile function and $20 \%$ had mild to moderate bowel symptoms ${ }^{(17,18)}$. The use of monoclonal antibodies along with chemoradiation is also being evaluated in the currently undergoing RTOG trials which will help the patients with over expression of tumour markers. Identifying molecular biomarkers predicting chemotherapy response using COXEN (co expression extrapolation) programme is in research for MIBC patients ${ }^{(19)}$. The role of immune checkpoint inhibitors (PD1, PDL-1) is also being evaluated in neoadjuvant, adjuvant and metastatic clinical setting. The tumour invasion of the immune system via regulation of T-cell activity is being studied. In NCT02710734, developed at Fox Chase Cancer Centre; cT2-cT4 urothelial carcinoma of the bladder treated with neoadjuvant AMVAC (accelerated methotrexate, vinblastine, doxorubicin and cisplatin) ${ }^{(20)}$.
Chemoradiotherapy using IMRT technique, and $5 F U$, mitomycin-C has shown to be well tolerated with improved DFS and complete response was seen in ATM, RB1 and FANCC genetic alterations. The use of EGFR, TKI has synergistic action with her 2-neu inhibitors both in-vitro and in-vivo enhancing radiosensitivity ${ }^{(21,22)}$.

\section{Conclusions}

Trimodality bladder preservation therapy must be judiciously advocated to the ideal bladder cancer cases. Selection of the patients is the most crucial step for better tumour control and improving quality of life in bladder cancer patients. Multidisciplinary clinics consisting of Urologists, Oncosurgeon, Radiation Oncologists, Medical Oncologists, Physicians and Anaesthetists must be formed and each case must be dealt critically for bladder preservation therapy as the patients have adequate local control and good quality of life. Team work is the key to success in Bladder cancer patients. With majority of patients being elderly, the use of radiation treatment provides equivalent oncologic outcomes and reduces the morbidity of radical cystectomy. Though difficult, randomised controlled trials of radical cystectomy and bladder preservation therapy must be carried out to draw clear conclusions for better patient care. Trimodality therapy should be offered to patients who are unfit for surgery and for those who are not willing to undergo any surgical procedures. Radical cystectomy must be reserved for recurrent cases and non-responders of chemoradiotherapy. The optimal usage of radiation technique, fractionation schedule, chemotherapeutic agent individualized for the patients and also targeted therapy will definitely bring about better results in management of bladder cancer.

\section{References}

1. Global cancer statistics 2018: GLOBOCAN estimates of bladder cancer.

2. Hospital Based Cancer Registry 2016: KMIO Data. 
3. Shipley WU, Kaufman DS, Heney NM et al. An update of combined modality therapy for patients with muscle invading bladder cancer using selective bladder preservation or cystectomy. J. Urol.162, 445-451 (1999).

4. Walker M, French SD, Doiron RC et al, Bladder sparing radiotherapy for muscle invasive bladder cancer: A survey of providers to determine barriers and enablers. Radiotherapy Oncol.2017:125:351-356.

5. Robert Huddart et al. Royal Marsden NHS Foundation Trust Study, Source- UK clinical trials gateway.

6. Smith Z.L, Christodouleas, J.P, Keefe SM, Malkowicz S.B, Guzzo T.J. Bladder preservation in the treatment of muscleinvasive bladder cancer: a review of the literature and a practical approach to therapy.BJU Int. 2013; 112: 13-25

7. Ploussard G, Daneshmand S, Efstathiou J.A et al. Critical analysis of bladder sparing with trimodal therapy in muscle-invasive bladder cancer: a systematic review. Eur Urol. 2014; 66: 120-137.

8. Garry D. Lewis, Waqar Haque et al.The Role Of Adjuvant Radiation Therapy in Locally Advanced Bladder Cancer,vol.4no.2pp.205213,2018.

9. Benjamin W. Fischer-Valuk, Jeff $M$. Michalski et al. Effectiveness of postoperative radiotherapy after radical cystectomy for locally advanced bladder cancer. Cancer Medicine, published by John Wiley and Sons Ltd.

10. Chahal R, Sundaram SK, Iddenden R, Forman DF, Weston PMT, Harrison SCW. A study of the morbidity, mortality and longterm survival following radical cystectomy and radical radiotherapy in the treatment of invasive bladder cancer in Yorkshire. Eur Urol 2003;43:246-57.

11. Galvin JM, Ezzell G, Eisbrauch A. Implementing IMRT in clinical practice: a joint document of ASTRO and AAPM. Int. J.
Radiat. Oncol. Biol. Phys.58(5), 1616-1634 (2002).

12. Cossmann PH. Advances in image-guided radiotherapy - the future is in motion. Eur. Oncol. Rev.62-66 (2005)

13. Naslund I, Nilsson B, Littbrand B. Hyperfractionated radiotherapy of bladder cancer. Acta Oncol.33, 397-402 (1994).

14. Stuschke M, Thames HD. Hyperfractionated radiotherapy of human tumors: overview of the randomized clinical trials. Int. J. Radiat. Oncol. Biol. Phys. 37, 259-267 (1997).

15. Kaufman D, Winter KA, Shipley WU et al. Muscle-invading bladder cancer, RTOG protocol 99-06: initial report of a Phase I/II trial of selective bladder-conservation employing TURBT, accelerated irradiation sensitized with cisplatin and paclitaxel followed by adjuvant cisplatin and gemcitabine chemotherapy (abstract). J. Clin. Oncol.26, 379S (2008).

16. Little FA, Howard GC. Sexual function following radical radiotherapy for bladder cancer. Radiother. Oncol.49, 157-161 (1998).

17. Koga F, Kihara K. Selective bladder preservation with curative intent for muscle invasive bladder cancer: A contemporary review. Int. J. Urol 2012:19:388-401.

18. Zietman Al, Saeco D, Skowronski V, Gomery $\mathrm{P}$ et al. Organ conservation in invasive bladder cancer by transurethral resection, chemotherapy and radiation: Results of urodynamic and quality of life study on long term survivors. J. Urol 2003;170:1772-1776.

19. Flaig TW et al and the Southwest Oncology Group and National Cancer Institute. S1314, Co-expression Extrapolation (COXEN) Program to Predict Chemotherapy Response in Patients with Bladder Cancer. In: Clinical trials.gov. NCT02177695, 2015.

20. Geynisman DM et al and the Fox Chase Cancer Center. Trimodal Bladder Preservation Therapy: Maximal Transurethral Resection Followed by Accelerated Methotraxate, Vinblastine, Doxorubicin, and 
Cisplatin (AMVAC) and Concurrent

Chemoradiation with Intensity Modulated

Radiation Therapy for Muscle Invasive

Bladder Cancer. In: Clinicaltrials.gov.

NCT02710734, 2016.

21. Chakravarti A, Winter $\mathrm{K}, \mathrm{Wu} \quad \mathrm{CL}$ et al. Expression of the EGFR and Her-2 are predictors of favorable outcome and reduced complete response rates, respectively, in patients with muscle-invading bladder cancers treated by concurrent radiation and cisplatin-based chemotherapy: a report from the RTOG. Int. J. Radiat. Oncol. Biol. Phys. 62, 309-317 (2005).

22. Tsai YC, Pei-Yin H, Tzen KY et al. Synergistic Blockade of EGFR and HER2 by New Generation EGFR Tyrosine Kinase Inhibitor Enhances Radiation Effect in Bladder Cancer Cells. Mol Cancer Ther 2015; 14(3):810-20. 